\title{
Panoramik radyografta farklı baş pozisyonlarının radyomorfometrik indekslere etkisi
}

\section{The effect of different head positioning in panoramic radiography on radiomorphometric indexes}

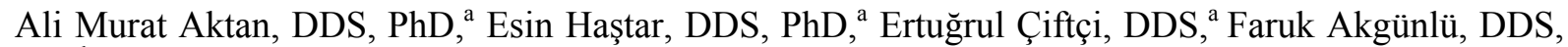 \\ $\mathrm{PhD}^{\mathrm{b}}$
}

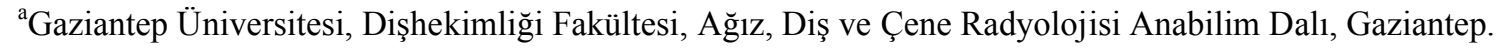

${ }^{\text {b} S e l c ̧ u k ~ U ̈ n i v e r s i t e s i, ~ D i s ̧ h e k i m l i g ̆ i ~ F a k u ̈ l t e s i, ~ A g ̆ ı z, ~ D i s ̧ ~ v e ~ C ̧ e n e ~ R a d y o l o j i s i ~ A n a b i l i m ~ D a l ı, ~ K o n y a . ~}$

Received: 10 May 2011 Accepted: 21 September 2011

\begin{abstract}
ÖZET
Amaç: Panoramik radyografide değişen horizontal ve vertikal baş rotasyonlarının mandibular kortikal genişlik (mental indeks) ve panoramik mandibular indeks ölçümleri üzerindeki etkilerini incelemektir.
\end{abstract}

Gereç ve Yöntem: Kadavradan alınan kafatasının doğal baş hareketlerini [sağa-sola çevirme hareketi (X düzlemi), aşağı-yukarı eğme hareketi (Y düzlemi) ve sağa-sola devirme hareketi ( $Z$ düzlemi)] üç boyutlu olarak taklit etmesine olanak sağlayan bir düzenek hazırlandı. $\mathrm{Bu}$ düzenekte her düzlemde $(+)$ ve (-) yönlerde 1, 2, 3, $4,5,6,7,8,9,10$ ve 15 derecelerde toplam 66 dijital panoramik radyogram elde edildi. Her radyografide radyomorfometrik indekslerden mental indeks ve panoramik mandibular indeks ölçümleri yapıldı.

Bulgular: $X$ düzleminde başın açısı 7 derece ve üstüne çıktığında, Y düzleminde $(+)$ yönde 7 derecenin üstüne çıktığında, (-) yönde ise açı 9 ve 11 derece değiştiğinde, $Z$ düzleminde hem $(+)$ hem de (-) yönde açı 6 ve 7 derece arttığında yapılan mental indeks ölçümleriyle ideal baş pozisyonu ölçümleri arasında istatistiksel olarak anlamlı farklılık belirlendi. Panoramik mandibular indeks ölçümlerinde ise $\mathrm{X}$ düzleminde ölçümlerin bazılarında, Y düzleminde başın $(+)$ yönde hareketi sırasında alınan panoramik radyografilerde özellikle açı 3 derece üzerine çıktığında yapılan ölçümlerle, $\mathrm{Z}$ düzleminde $(+)$ yönde açının 1, 6 ve 7 derece artışındaki ölçümler ideal baş pozisyonundaki ölçümlerden farklı olarak bulundu.

Sonuçlar: Panoramik radyografideki ölçümlerin doğru olabilmesi için hastanın başının uygun pozisyonlandırılması gerekmektedir.

Anahtar kelimeler: Mental indeks, panoramik mandibular indeks, panoramik radyografi, asimetri indeksi.

\begin{abstract}
Objectives: The purpose of this study was to examine the effect of varying horizontal and vertical head rotations on measurements of the panoramic mandibular index and mental index (cortical width of mandibula) on panoramic radiography.

Material and Methods: It was designed a mechanism that could imitate natural head movements (the right-left turn movement/X-plane, tilt up and down movement/Y-plane and right-toside tilting movement/ Z-plane) in three dimensions of the skull taken from cadavers. In this model, it was obtained a total of 66 digital panoramic radiographs with $1,2,3,4,5,6,7,8,9,10$ and 15 degrees on each plane (+) and (-) directions. Mental and panoramic mandibular index were measured on each radiograph.
\end{abstract}

Results: When the angle of the head increases above 7 degrees in the X-plane and on $(+)$ direction of the Y-plane, 9 and 11 degrees on (-) direction of the Y-plane, 6 and 7 degrees on both $(+)$ and (-) direction of the Z-plane, the mental index measurements were different statistically significant from measurements of the ideal head position. In some of the measurements in the X plane and when the angle of the head increases above 3 degrees on $(+)$ direction in the Y plane, 1, 6 and 7 degrees on $(+)$ direction in the $\mathrm{Z}$ plane and, the panoramic mandibular index measurements were different statistically significant from measurements of the ideal head position.

Conclusion: For true measurements on panoramic radiography, proper positioning of the patient's head is important.

Key words: Mental index, panoramic mandibular index, panoramic radiography, assymetry index. 
Esin HAŞTAR

Gaziantep Üniversitesi, Dişhekimliği Fakültesi

Ağız, Diş ve Çene Radyolojisi AD,

Şehitkamil, Gaziantep

Tel:+903423606060 / 76610

Fax: 03423610610

e-mail:dtesin@hotmail.com

\section{GíRiş}

Her yıl çok sayıda panoramik radyografi dental hastalıkları incelemek için alınmaktadır. Ayrıca osteoporoz gibi iskelet sistemini etkileyen hastalığı olan kişilerin tedavi önceliğini saptamak içinde son zamanlarda yaygın olarak kullanılmaktadir. Panoramik radyografilerde mental indeks (MI=kortikal genişlik) ve panoramik mandibular indeks (PMI) gibi mandibulanın kortikal indisleri genel iskeletin kemik mineral yoğunluğu ile önemli ölçüde ilişkilidir. $\mathrm{Bu}$ nedenle indislerin birçoğu rezorpsiyonun sinyallerini gözlemlemek ve kemik kalitesini değerlendirmek için kullanılmaktadır. ${ }^{1-8}$

Panoramik radyografi, dişlerin ve ilgili yapıların devamlılığını bir radyografi üzerinde elde etmek amaciyla çenelerin tümünü bir düzlem üzerinde kaydeden bir tekniktir. Dar bir X-ışını demeti çeneleri dairesel olarak izlerken, görüntü yine hareket eden bir film yüzeyine kaydedilir. ${ }^{9,10} \mathrm{Bu}$ teknikten dolayı her iki boyutta da belirli bir miktarda büyüme söz konusudur. $\mathrm{Bu}$, fokal spot-obje ve objefilm uzaklıklarından etkilenerek vertikal ve horizontal büyüme olarak karşımıza çıkmaktadır. ${ }^{11}$

Görüntüdeki magnifikasyon ve distorsiyon panoramik radyografideki boyutsal doğruluğu sınırlandırmaktadır. Magnifikasyon, obje derinliği ve dentisyonun anterior bölgesinden posterior bölgesine değişiklik oluşturur. Fokal olukla ilişkili olarak objenin pozisyonundaki minör değişikliklerle magnifikasyondaki geniş varyasyonlar nedeniyle panoramik film üzerinde horizontal boyutlar özellikle anterior bölgede güvenilmezdir. ${ }^{12}$ Panoramik radyogafilerde dikey büyümenin birçok faktöre bağlı olarak ortaya çıtığı saptanmıştır. Bunlar, genel olarak başın pozisyonlanmasindaki farklılıklardan kaynaklanmaktadır. ${ }^{11}$

Çeşitli araştırmacıların görüntü tabakası, projeksiyon açısı, horizontal ve vertikal magnifikasyon, açısal distorsiyon ve hasta pozisyonlandırmasinın panoramik görüntülerin boyutsal doğruluğu üzerindeki etkileriyle ilişkili çalışmaları vardır. ${ }^{13-25}$

Panoramik osteoporozun radyografilerde kullanılan mental indeks ve panoramik mandibular indeks gibi indekslerle ilgili yapılmış çok sayıda çalışma vardır. ${ }^{1-8}$ Fakat bu indeks değerlerinde panoramik radyografideki hasta pozisyonlandirmasına bağlı oluşan magnifikasyon ve distorsiyonun etkilerini inceleyen bir çalışma yoktur.

$\mathrm{Bu}$ nedenle bu çalışmanın amacı panoramik radyografide mandibular kortikal genişlik (mental indeks) ve panoramik mandibular indeks ölçümleri üzerinde değișen horizontal ve vertikal baş rotasyonlarının etkilerini incelemek ve bu bulguları ideal baş pozisyonundaki ölçümlerle karşılaştırmaktır.

\section{GEREÇ VE YÖNTEM}

\section{Düzeneğin Hazırlanması}

Selçuk Üniversitesi Tıp Fakültesi Anatomi Anabilim Dalından temin edilen kadavra alt ve üst çeneleri plastik kafa modeline soğuk akrilik ile monte edildi. Modele radyografi işlemleri sırasında, yumuşak dokuyu taklit etmek için iki mm'lik pembe mum ve bir mm'lik soğuk akrilik, çeneler üzerine yerleştirildi. Hazırlanan modelin doğal baş hareketlerini üç boyutlu olarak sağa-sola çevirme hareketi (X düzlemi), aşağı-yukarı eğme hareketi (Y düzlemi) ve sağa-sola devirme hareketi ( $\mathrm{Z}$ düzlemi) taklit etmesine olanak sağlayan düzenek, radyogram üzerinde artefakt oluşturmaması için teflondan hazırlatıldı. $\mathrm{Bu}$ düzenek, modele 
bahsedilen üç yönde de birer derece hareket olanağı sağlayacak tarzda hazırlatıld1. Düzeneğin uzun parçası kafa modelinin foramen magnumuna yerleştirilerek sıcak silikon ile sabitlendi (Resim 1).

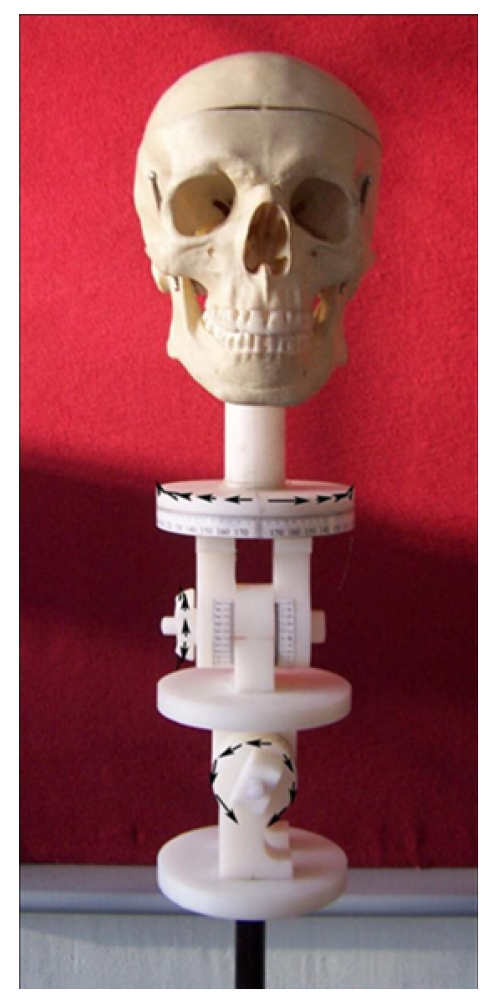

Resim 1. Hazırlanan modelin doğal baş hareketlerini üç boyutlu olarak sağa-sola çevirme hareketi (X düzlemi), aşağı-yukarı eğme hareketi (Y düzlemi) ve sağa-sola devirme hareketi ( $\mathrm{Z}$ düzlemi) taklit etmesine olanak sağlayan düzenek.

$\mathrm{Bu}$ çalışmada kullanılan düzeneğe monte edilen kafa modeline aşağıdaki üç düzlem üzerinde ayrı ayrı olmak üzere birer derece hareket verildi. X düzlemi: Hasta başının devirme ve eğme hareketi yapmadan sağa $(+)$ veya sola (-) doğru çevirme hareketi yapması (Resim 2a). Y düzlemi: Hasta başının çevirme ve devirme hareketi yapmadan aşağıya $(+)$ veya yukarıya (-) doğru eğme hareketi yapması (Resim 2b). Z düzlemi: Hasta başının sağa (+) veya sola (-) doğru çevirme ve eğme hareketi yapmadan devirme hareketi yapmas1 (Resim 2c).

\section{Dijital Panoramik Radyografi}

Panoramik radyografi cihazının fokal throught yerleştirilen düzeneğin radyografik çekimleri sırasında uygun değer standardizasyon sağlamak amacıyla, $X, Y$ ve $Z$ düzlemleri sifir pozisyonda iken, Frankfurt horizontal düzleminin yere paralel olmasına ve 1sırma çubuğunun uygun konumda isırıldığına dikkat edildi. İlk panoramik görüntü $\mathrm{X}, \mathrm{Y}$ ve $\mathrm{Z}$ düzlemlerinin 0 derece olduğu konumda alınd. Daha sonra iki düzlem sabit tutularak bir düzlemde $(+)$ ve $(-)$ yönlerde $1,2,3,4,5,6,7,8,9,10$ ve 15 derecelerde 11 defa radyografi alınd 1 ve bu işlem diğer iki düzlem için de tekrarlandı. Böylece toplam 66 dijital panoramik radyogram elde edilmiş oldu. $\mathrm{Z}$ düzleminde 7 dereceden sonra alınan radyografilerde ölçüm yapılamayacak kadar kötü dijital radyogramlar elde edildiği için bunlar çalışmaya dahil edilmedi. Bütün panoramik radyografi işlemleri $40 \mathrm{kvp}, 4$ $\mathrm{mA}$ ve 13,6 sn'lik manuel parametreler kullanılarak bir dijital panoramik röntgen cihazı ile alındı (Kodak 8000 Dijital Panoramik Sistem, Trophy Radiologies, Carestream Health, Inc, Rochester NY, Amerika).

$X, Y$ ve $Z$ düzlemlerinin 0 derece olduğu konum ideal baş pozisyonu olarak belirlendi.

\section{Radyomorfometrik indeks ölçümler}

Radyomorfometrik indekslerden Mental indeks (MI) ve Panoramik Mandibular indeks'lerin (PMI) ölçümleri deneyimli bir oral radyolog tarafından gerçekleştirildi. Ölçümler mandibulanın sağ ve sol tarafında yapıldı ve bu ölçümlerin ortalaması alınd1. MI: Ledgerton ve ark.'lar1 $^{26}$ tarafından belirtilen yönteme göre radyografi üzerinde mental foramen saptandiktan sonra, mental foramen merkezi ile mandibulanın alt sınırının teğeti dik bir çizgi ile birleştirilerek bu 


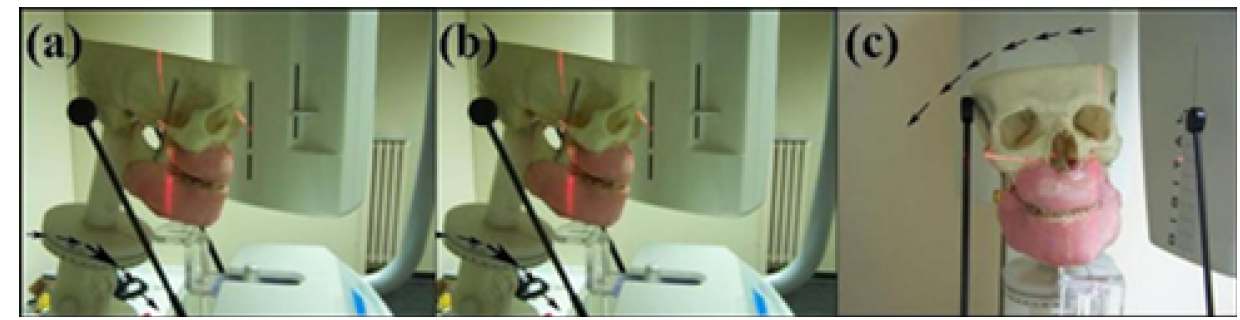

Resim 2. X, Y ve Z düzlemlerinde hazırlanan düzeneğin sırasıyla sağa (+) veya sola (-) doğru çevirme hareketi aşağıya $(+)$ veya yukarıya (-) doğru eğme hareketi sağa $(+)$ veya sola (-) doğru çevirme ve eğme hareketi yapmadan devirme hareketi yapması gösterilmektedir.

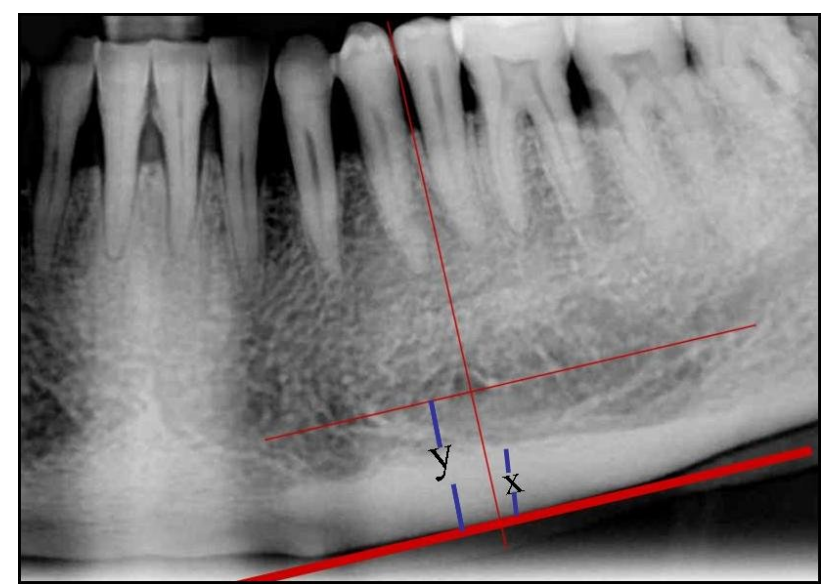

Resim 3. MI: radyografi üzerinde mental foramen saptandiktan sonra, mental foramen merkezi ile mandibulanın alt sınırının teğeti dik bir çizgi ile birleştirilerek bu çizgi üzerinde mandibulanın kortikal genişlik ölçümü yapılmaktadır (x). PMI: mandibular korteks kalınlığının (x) mental foramen ile inferior mandibular korteks arasındaki uzaklığına (y) olan oranidir $(\mathrm{x} / \mathrm{y})$.

üzerinde mandibulanın kortikal genişlik ölçümü yapılmaktadır. PMI: Benson ve ark.'ları $^{27}$ tarafindan tanımlanan PMI, mandibular korteks kalınlığının mental foramen ile inferior mandibular korteks arasındaki uzaklığa olan oranıdır (Resim $3)$.

\section{İstatistiksel Analiz}

İstatistiksel analizler SPSS V.13.0. istatistik yazılımı ile gerçekleştirildi (SPSS Inc. Chicago, IL, ABD). Eşleştirilmiş ttesti ideal baş pozisyonundaki indeks ölçüm değerleriyle birer derece sağa-sola çevirme hareketi (X düzlemi), aşağı-yukarı eğme hareketi (Y düzlemi) ve sağa-sola devirme hareketi ( $\mathrm{Z}$ düzlemi) esnasında alınan panoramik radyografilerdeki ölçümlerin karşılaştırılmasında kullanıldı.

\section{BULGULAR}

$\mathrm{X}$ düzleminde sağa ve sola çevirme hareketinde başın açısı 7 derece ve üstüne çıktığında yapılan mental indeks ölçümleriyle ideal baş pozisyonu ölçümleri arasında istatistiksel olarak anlamlı farklılık belirlendi $(\mathrm{p}<0.05)$. Aynı düzlemde panoramik mandibular indeks ölçümlerinde ise sağa ve sola doğru başın çevrilmesiyle ölçümlerin bazılarında istatistiksel olarak anlamlı farklılık belirlendi $(\mathrm{p}<0.05)$ (Tablo 1). 
Tablo 1. Sağa-sola çevirme hareketi (X düzlemi) esnasında yapılan indeks ölçümlerinin ideal baş pozisyonundaki (x, y, z 0 derecede) ölçümlerle karşılaştırılmasında ortalama farklılıklar.

\begin{tabular}{|c|c|c|c|c|}
\hline & \multicolumn{2}{|c|}{ Mí } & \multicolumn{2}{|c|}{ PMİ } \\
\hline & Sd & $\mathbf{P}$ & Sd & $\mathbf{P}$ \\
\hline xyz0/x-1 & 0,023 & 0,07 & 0.02 & 0,08 \\
\hline xyz0/x-2 & 0,038 & 0,05 & 0.03 & $0,01 *$ \\
\hline xyz0/x-3 & 0,018 & 0,18 & 0.01 & 0,12 \\
\hline$x y z 0 / x-4$ & 0,023 & 0,19 & 0.02 & 0,14 \\
\hline xyz0/x-5 & 0,016 & $0,04 *$ & 0.01 & 0,14 \\
\hline xyz0/x-6 & 0,016 & 0,13 & 0.01 & 0,19 \\
\hline xyz0/x-7 & 0,026 & 0,14 & 0.02 & $0,04 *$ \\
\hline xyz0/x-8 & 0,011 & $0,03 *$ & 0.01 & 0,36 \\
\hline xyz0/x-9 & 0,001 & 0,07 & 0.00 & 0,84 \\
\hline $\mathrm{xyz0} / \mathrm{x}-10$ & 0,085 & $0,00 *$ & 0.08 & $0,01 *$ \\
\hline $\mathrm{xyz0} / \mathrm{x}-15$ & 0,006 & $0,00^{*}$ & 0.00 & 0,05 \\
\hline xyz0/x 1 & 0,013 & 0,33 & 0.01 & 0,44 \\
\hline xyz0/x 2 & 0,031 & 0,18 & 0.03 & 0,19 \\
\hline xyz0/x 3 & 0,031 & $0,03 *$ & 0.03 & $0,01 *$ \\
\hline xyz0/x 4 & 0,013 & 0,47 & 0.01 & 0,2 \\
\hline xyz0/x 5 & 0,033 & 0,06 & 0.03 & $0,01 *$ \\
\hline xyz0/x 6 & 0,025 & 0,12 & 0.02 & 0,34 \\
\hline xyz0/x 7 & 0,015 & 0,22 & 0.01 & 0,22 \\
\hline xyz0/x 8 & 0,021 & $0,02 *$ & 0.02 & 0,09 \\
\hline xyz0/x 9 & 0,025 & $0,03 *$ & 0.02 & 0,16 \\
\hline xyz0/x 10 & 0,063 & $0,00 *$ & 0.06 & $0,00 *$ \\
\hline xyz0/x 15 & 0,126 & $0,00 *$ & 0.12 & $0,00 *$ \\
\hline
\end{tabular}

$* p<0,05$, Sd:Ortalama Farklilık

Y düzleminde aşağı ve yukarı eğme hareketinde başın açısı $\quad(+)$ yönde 7 derecenin üstüne çıktığında mental indeks ölçümleriyle ideal baş pozisyonu ölçümleri arasında istatistiksel olarak anlamlı farklılık belirlendi $(\mathrm{p}<0.05)$. (-) yönde ise açı 9 ve 11 derece değiştiğinde yapılan mental indeks ölçümleri ideal baş pozisyonu ölçümlerinden farklıydı. Aynı düzlemde başın yukarı doğru kaldırılması sırasında alınan panoramik radyografilerdeki panoramik mandibular indeks ölçümleriyle ideal baş pozisyonu ölçümleri arasında istatistiksel olarak anlamlı farklılık belirlenmedi $(p>0.05)$. Başın aşağı doğru açılandırılması sırasında alınan radyografilerde özellikle açı 3 derece üzerine çıktığında yapılan panoramik mandibular indeks ölçümlerinin ideal baş pozisyonundaki panoramik mandibular indeks ölçümünden istatistiksel olarak anlamlı farklı olduğu belirlendi $(\mathrm{p}<0.05)$ (Tablo 2).

Başın sağa-sola devrilme hareketi sirasinda hem (+) hem de (-) yönde açı 6 ve 7 derece arttığında mental indeks ölçümlerinin ideal baş pozisyonundaki ölçümlerden istatistiksel olarak anlamlı farklı olduğu tespit edildi $(\mathrm{p}<0.05)$. Panoramik mandibular indeks ölçümlerinde ise $(+)$ yönde açının 1, 6 ve 7 derece artışındaki ölçümler ideal baş pozisyonundaki ölçümlerden farklı olarak bulundu (Tablo 3). 
Tablo 2. Aşağı-yukarı eğme hareketi (Y düzlemi) esnasında yapılan indeks ölçümlerinin ideal baş pozisyonundaki (x, y, z 0 derecede) ölçümlerle karşılaştırılmasında ortalama farklılıklar.

\begin{tabular}{|c|c|c|c|c|}
\hline & \multicolumn{2}{|c|}{ Mí } & \multicolumn{2}{|c|}{ PMİ } \\
\hline & Sd & $\mathbf{P}$ & Sd & $\mathbf{P}$ \\
\hline xyz0/y-1 & 0,3 & 0,1 & 0.02 & 0,27 \\
\hline xyz0/y-2 & 0,25 & 0,13 & 0.01 & 0,11 \\
\hline$x y z 0 / y-3$ & 0,06 & 0,63 & -0.00 & 0,91 \\
\hline$x y z 0 / y-4$ & 0,26 & 0,15 & 0.00 & 0,82 \\
\hline$x y z 0 / y-5$ & 0,26 & 0,06 & 0.02 & 0,07 \\
\hline xyz0/y-6 & 0,23 & 0,19 & 0.00 & 0,89 \\
\hline$x y z 0 / y-7$ & 0,23 & 0,11 & -0.00 & 0,78 \\
\hline xyz0/y-8 & 0,56 & $0,04^{*}$ & -0.00 & 0,46 \\
\hline$x y z 0 / y-9$ & 0,5 & $0,04 *$ & -0.01 & 0,28 \\
\hline xyz0/y-10 & 1,63 & $0,00 *$ & -0.00 & 0,67 \\
\hline xyz0/y-15 & 2,2 & $0,00 *$ & 0.00 & 0,54 \\
\hline xyz0/y 1 & 0,06 & 0,27 & 0.02 & 0,06 \\
\hline xyz0/y 2 & $-0,03$ & 0,85 & 0.02 & 0,25 \\
\hline xyz0/y 3 & $-0,01$ & 0,9 & 0.02 & 0,13 \\
\hline xyz0/y 4 & $-0,03$ & 0,63 & 0.02 & $0,04 *$ \\
\hline xyz0/y 5 & 0,03 & 0,86 & 0.04 & 0,07 \\
\hline xyz0/y 6 & 0 & 1 & 0.04 & $0,01 *$ \\
\hline xyz0/y 7 & 0,2 & 0,07 & 0.05 & $0,02 *$ \\
\hline xyz0/y 8 & 0,1 & 0,43 & 0.04 & $0,03 *$ \\
\hline xyz0/y 9 & 0,31 & $0,04 *$ & 0.05 & 0,09 \\
\hline xyz0/y 10 & 0,26 & 0,1 & 0.06 & $0,00^{*}$ \\
\hline xyz0/y 15 & 0,58 & $0,00 *$ & 0.07 & $0,00^{*}$ \\
\hline
\end{tabular}

${ }^{*} \mathrm{p}<0,05$, Sd:Ortalama Farkl111k

\section{TARTIŞMA}

Panoramik radyografilerde farklılaşmış trabeküler yapı ile osteoporoz arasında ilişki olduğunu bildiren çalışmalar vardır. $\mathrm{Bu}$ çalışmalarda mental indeks (mandibular kortikal kalınlık), panoramik mandibular indeks gibi radyomorfometrik indekslerin hastanın osteoporoz riskini değerlendirmekte kullanılabileceği rapor edilmiştir. $^{1-8} \mathrm{Bu}$ çalışmada panoramik görüntüler 1şığında bireylerdeki düşük kemik mineral densite varlığının belirlenmesinde hasta baş pozisyonunun panoramik görüntü üzerine etkisi araştırılmıştır.

Panoramik radyografi geniş anatomik bölgenin görüntülenmesi, nispeten düşük hasta radyasyon dozu, rahatlık, kolaylık ve hızlı olması gibi avantajlarının yanında dezavantajları da olan bir radyografi yöntemidir. En önemli dezavantajlarından biri görüntüde kalıcı değişken magnifikasyon ve geometrik distorsiyondur. Panoramik görüntü tabakası içerisinde sadece merkezi olarak yerleşmiş yapılar eşit horizontal ya da 
Tablo 3. Sağa-sola devirme hareketi ( $Z$ düzlemi) esnasında yapılan indeks ölçümlerinin ideal baş pozisyonundaki (x, y, z 0 derecede) ölçümlerle karşılaştırılmasında ortalama farklılıklar.

\begin{tabular}{|c|c|c|c|c|}
\hline & \multicolumn{2}{|c|}{ Mí } & \multicolumn{2}{|c|}{ PMİ } \\
\hline & Sd & $\mathbf{P}$ & Sd & $\mathbf{P}$ \\
\hline xyz0/z-1 & $-0,06$ & 0,27 & 0,008 & 0,03 * \\
\hline xyz0/z-2 & 0 & 1 & 0,01 & 0,42 \\
\hline xyz0/z-3 & $-0,01$ & 0,84 & 0,003 & 0,77 \\
\hline xyz0/z-4 & $-0,01$ & 0,74 & 0,006 & 0,27 \\
\hline xyz0/z-5 & 0,15 & 0,09 & 0,005 & 0,22 \\
\hline xyz0/z-6 & 0,45 & $0,00 *$ & 0,048 & $0,00^{*}$ \\
\hline $\mathbf{x y z 0} / \mathbf{z}-7$ & 0,58 & $0,01 *$ & 0,045 & 0,01 * \\
\hline xyz0/z 1 & 0,05 & 0,58 & 0,018 & 0,17 \\
\hline xyz0/z 2 & 0 & 1 & 0,025 & 0,1 \\
\hline $\mathbf{x y z 0} / \mathbf{z} 3$ & 0,16 & 0,18 & 0,036 & 0,08 \\
\hline$x y z 0 / z 4$ & 0,05 & 0,58 & 0,021 & 0,03 * \\
\hline xyz0/z 5 & 0,4 & 0,08 & 0,055 & 0,06 \\
\hline$x y z 0 / z 6$ & 0,81 & $0,00 *$ & 0,038 & 0,06 \\
\hline xyz0/z 7 & 0,68 & $0,03^{*}$ & 0,053 & 0,08 \\
\hline
\end{tabular}

${ }^{*} \mathrm{p}<0,05$, Sd:Ortalama farklılık

vertikal magnifikasyona sahiptir. Görüntü tabakasından uzakta olan objeler eşit olmayan magnifikasyona sahip olacaktır. $^{11,28}$

Hasta başının uygun olmayan pozisyonlanması sonucu görüntülenmek istenen anatomik yapıların görüntü tabakası (fokal throught) dışında olmasının mandibular inferior korteksin görünümünü etkileyebileceği düşünüldü. $\mathrm{Bu}$ nedenle değişen baş pozisyonunun osteoporoz ile ilgili yapılan indeks ölçüm verileri üzerine etkisinin değerlendirilmesi amaciyla bu çalışma planlandı.

Yapılmış çalışmalar panoramik radyografi çekimi sırasında hasta pozisyonundaki küçük anteroposterior değişmeler $\left( \pm 5^{\circ}\right)$ ve eğilmelerin $\left( \pm 5^{\circ}\right)$ vertikal ölçümlerde $\% 2$ den daha az varyasyonlara neden olduğunu göstermiştir. Mental indeks ve panoramik mandibular indeks yaklaşık olarak bu düzlemde yapılan bir ölçümdür ve radyografi çekimi sırasında hasta pozisyonlandırılmasına dikkat edildiği sürece distorsiyonel etkilerinin kortikal ölçüm üzerinde çok az bir etkisi olacağ muhtemeldir. ${ }^{5,15}$ Mevcut çalışmada X ve Y düzleminde anteroposterior ve sağ-sol yönde eğilme derecesi 7'nin üzerine çıktığında alınan panoramik radyografilerde yapilan mental indeks ve panoramik mandibular indeks ölçümleri ideal baş pozisyonundaki ölçümlerden istatistiksel olarak anlamlı farklı olması bu bilgiyi doğrulamaktadır $\quad(p<0.05) . \quad Z$ düzleminde ise 5 derecenin üzerinde alınan panoramik radyografilerdeki mental indeks ölçümleri ile 5 derecenin üzerindeki derecelerde sağa doğru eğilme hareketi sırasında alınan radyografilerdeki panoramik mandibular indeks ölçümleri ideal baş pozisyonundaki ölçümlerden istatistiksel olarak anlaml derecede farkliyd $1(\mathrm{p}<0.05)$. 
Bunun yanında dental panoramik radyografinin, yapıların doğru ölçülmesi için yetersiz olduğu düşünülmektedir. $\mathrm{Bu}$ durum işınlama sırasında hasta hareketiyle ilişkili hatalar ve kafa pozisyonunun doğru olmamasına bağlıdır. Sanderink ve arkadaşlarına göre dental panoramik radyografların güvenilmez olmasının nedeni $X$ 1şınının yolu ve rotasyon merkeziyle ilgili olarak çenelerin pozisyonuyla açıklanabilecektir. $\mathrm{Bu}$ çalışmada güvenilmezliğin nedeninin hastanın başının arkaya doğru rotasyonu nedeniyle olduğu ve sagital düzlemde (Y düzlem) 10 dereceye kadar lateral eğimlerin ihmal edilebilir etkiye sahip olduğu rapor edilmiştir. ${ }^{12,29}$ Mevcut çalışmada Y düzlemindeki ölçümler değerlendirildiğinde Sanderink ve arkadaşlarının $^{29}$ çalışmalarından farklı olarak mental indeks ölçümleri için 7 derecenin üzerindeki ölçümlerde, panoramik mandibular indeks ölçümleri için sadece (-) yönde (arkaya doğru konumlanmada) 3 derece üzerindeki ölçümlerin bazılarında ideal baş pozisyonundaki ölçümlere göre istatistiksel anlamlı fark belirlenmiştir $(p<0.05)$.

Daha önceki çalışmalar bir diş ve yerleşik bir referans düzlemi arasında her iki yönde 2,5 derece varyasyon radyografın kullanımında klinik amaçlar için ciddi bir engel meydana getirmeyeceğini rapor etmiştir. Bu klinik olarak önemli tolerans limitlerinin uygulaması dört baş pozisyonunda maksiller ve mandibular görüntü açılarının \% 53'ünün ideal baş pozisyonundaki görüntü açılarından klinik olarak önemli farklı olduğunu açığa çıkarmıştır. Horizontal baş rotasyonu horizontal ve vertikal magnifikasyonun derecelerinde değişime neden olan objefilm ve 1şın kaynağı-obje aralıklarını değiştirir. Horizontal baş rotasyonu aynı zamanda ışı projeksiyon açısını değiştirir. $^{28,29}$ Mevcut çalışmada üç düzlemde farklı derecelerde konumlandırılmış baş modelinden alınan panoramik radyografilerde her düzlem için değişen derecelerdeki yapılan indeks ölçümlerinin ideal baş pozisyonundaki ölçümlerden istatistiksel olarak anlamlı farkl1lık $(p<0.05)$ olması horizontal baş rotasyonuna bağlanabilir.

Panoramik radyografiler hassas ölçümlerde ya da göreceli karşılaştırmalarda ihtiyatlı kullanılmalıdır. ${ }^{30}$ Nicel olarak bir hastanın farklı panoramik radyogramları ne zaman karşılaştırılırsa karşılaştırılsın hastanın başının doğru pozisyonlandırılması gerekli bir ön koşuldur. ${ }^{31}$ Buna ilave olarak bir çalışmada, uygun hasta pozisyonunda elde edilen panoramik radyogramlar üzerinde yapılan mandibular açısal ölçümlerin yüksek derecede doğruluk gösterdiği rapor edilmiştir. ${ }^{32} \mathrm{Bu}$ nedenle hastanın başının radyografi işlemi sırasında uygun konumlandırılması önemlidir. Baş pozisyonlandırılması için röntgen cihazının rehberleri dikkatli kullanılmalıdır. Özel tasarlanmış kafa tutucu kullanılması kafanın stabilizasyonunu sağlayacağından başın tekrarlanabilir yatay ve dikey dönme hareketlerinin geçerliliğini sağlar. ${ }^{33}$

Mevcut çalışmada her üç düzlemde değişen derecelerde başın konumlandırılması sırasında elde edilen, ideal baş pozisyonundaki ölçümlerden anlamlı olarak farklı olan bu panoramik mandibular indeks ölçümlerinin dereceleri arasında doğrusal bir ilişki yoktur. Fakat mental indeks ölçümleri için nispeten $X$ ve $\mathrm{Y}$ düzlemlerinde 7 derecenin üzerinde, $\mathrm{Z}$ düzleminde ise 5 derecenin üzerindeki ölçümlerde istatistiksel olarak anlamlı farklılık olması $(p<0.05)$, nispeten açının derecesi arttıkça ölçümün ideal baş pozisyonundaki ölçümden anlamlı ölçüde farklı olduğunu göstermiştir.

Hasta başının uygun olmayan pozisyonlamas1 sonucu görüntülenmek istenen anatomik yapıların görüntü tabakası dişında olması mandibular inferior korteksin görünümünü etkilediğinden ideal baş pozisyonundaki indeks ölçümleri uygun olmayan pozisyonlardaki ölçümlerden anlamlı ölçüde farklıdır. Bu nedenle panoramik radyografilerde, ölçümlerin doğru olabilmesi için hastanın 
başının uygun pozisyonlandırılması önemlidir.

\section{SONUÇ}

Çalışmanın verileri ışığında aşağıdaki sonuçlar ortaya çıkmıştır:

1. Hasta başının idealden 7 derece ve üzerinde sağa ve sola veya yukarıya doğru çevrilmesi durumunda MI ve PMİ gibi kemik mineral ölçüm indekslerine güvenilmez. 7 derece altındaki hareketlerde MI vePMI ölçümlerine güvenilebilir.

2. Hasta başının idealden 3 derece ve üzerinde aşağı doğru çevrilmesi durumunda MI ve PMİ gibi kemik mineral ölçüm indekslerine güvenilmez.

3. Hasta başının sağa ya da sola devrilmesi sırasında, açı hem $(+)$ hem de () yönde 6 ve 7 derece artacağ PMİ gibi kemik mineral ölçüm indekslerine güvenilmez.

4. Panoramik radyografideki ölçümlerin doğru olabilmesi için hastanın başının uygun pozisyonlandırılması gerekmektedir.

\section{KAYNAKLAR}

1. Zlataric DK, Celebic A. Clinical bone densitometric evaluation of the mandible in removable denture wearers dependent on the morphology of the mandibular cortex. J Prosthet Dent 2003;90:86-91.

2. Klemetti E, Kolmakow S, Kroger H. Pantomography in assessment of the osteoporosis risk group. Scand J Dent Res 1994;102:68-72.

3. Taguchi A, Tsuda M, Ohtsuka M, Kodama I, Sanada M, Nakamoto T Inagaki K, Noguchi T, Kudo Y, Suei Y, Tanimoto K, Bollen AM. Use of dental panoramic radiographs in identifying younger postmenopausal women with osteoporosis. Osteoporos Int 2006;17:387-394. [CrossRef]

4. Horner K, Devlin H. The relationship between mandibular bone mineral density and panoramic radiographic measurements. J Dent 1998;26:337343. [CrossRef]

5. Devlin $H$, Horner $K$. Mandibular radiomorphometric indices in the diagnosis of reduced skeletal bone mineral density. Osteoporos Int 2002;13:373-378. [CrossRef]

6. Drozdzowska B, Pluskiewicz W, Tarnawska B. Panoramic-based mandibular indices in relation to mandibular bone mineral density and skeletal status assessed by dual energy $\mathrm{X}$-ray absorptiometry and quantitative ultrasound. Dentomaxillofac Radiol 2002;31:361-367. [CrossRef]

7. Vlasiadis KZ, Skouteris CA, Velegrakis GA, Fragouli I, Neratzoulakis JM, Damilakis J, Koumantakis EE. Mandibular radiomorphometric measurements as indicators of possible osteoporosis in postmenopausal women. Maturitas 2007;58:226-235. [CrossRef]

8. Taguchi A, Sanada M, Krall E, Nakamoto T, Ohtsuka M, Suei Y, Tanimoto K, Kodama I, Tsuda M, Ohama K. Relationship between dental panoramic radiographic findings and biochemical markers of bone turnover. J Bone Miner Res 2003;18:1689-1694. [CrossRef]

9. Angulo F. La radiografia panoramica en pacientesedentulos y parcialmente edentulos. Acta Odontol Venez 1989;27:60.

10. Mc David WD, Tronje G, Welander U. A method tomaintain a constant magnification factor throughout the exposureof rotational panoramic radiographs. Dentomaxillofac Radiol 1989;18:160.

11. Akgünlü F, Kansu Ö. Panoramik radyograflarda görüntünün büyümesine neden olan faktörlerin matematiksel analizi mandibuler dikey büyüme. Cumhuriyet Üni Dişhek Fak Derg 2000;3(2):105-109.

12. Stramotas S, Geenty JP, Petocz $P$, Darendeliler MA. Accuracy of linear and angular measurements on 
panoramic radiographs taken at various positions in vitro. Eur $J$ Orthod 2002;24(1):43-52. [CrossRef]

13. Lucchesi MV, Wood RE, Nortje CJ. Suitability of the panoramic radiograph for assessment of mesiodistal angulation of teeth in the buccal segment of the mandible. Am J Orthod Dentofacial Orthop 1988;94:303-310. [CrossRef]

14. Ursi W, Almeida $R$, Tranano $O$, Henriques J. Assessment of mesiodistal axial inclination through panoramic radiography. J Clin Orthod 1990;24:166-173.

15. Xie Q, Soikkonen K, Wolf J, Mattila K, Gong M, Ainamo A. Effect of head positioning in panoramic radiography on vertical measurements: an in vitro study. Dentomaxillofac Radiol 1996:25:61-66.

16. McDavid WD, Tronje G, Welander U, Morris CR, Nummikoski P. Imaging characteristics of seven panoramic $\mathrm{X}$ ray units. Dentomaxillofac Radiol 1985;8(suppl):1-68.

17. Samfors KA, Welander U. Angle distortion in narrow beam rotation radiography. Acta Radiol 1974;15:570-576.

18. Tronje G, Welander U, McDavid WD, Morris CR. Image distortion in rotational panoramic radiography: III. Inclined objects. Acta Radiol 1981;22:585-592.

19. Samawi SSB, Burke PH. Angle distortion in orthopantomogram. Br J Orthod 1984;11:100-107.

20. Lund TM, Manson-Hing LR. A study of the focal troughs of three panoramic dental x-ray machines: Part 1. The area of sharpness. Oral Surg Oral Med Oral Pathol 1975;39:318-328.

21. Lund TM, Manson-Hing LR. A study of the focal troughs of three panoramic dental x-ray machines: Part 2. Image dimensions. Oral Surg Oral Med Oral Pathol 1975;39:647-653.

22. Schiff T, D'Ambrosio J, Glass BJ, Langlais RP, McDavid WD. Common positioning and technical errors in panoramic radiography. J Am Dent Assoc 1986;113:422-426.

23. Lund TM, Manson-Hing LR. Relations between tooth positions and focal troughs of panoramic machines. Oral Surg Oral Med Oral Pathol 1975;40:285-293.

24. Welander U, Wickman G. Blurring and image layer thickness in narrow beam rotational radiography. Acta Radiol 1977;18:705-714.

25. Glass BJ, McDavid WD, Welander U, Morris CR. The central plane of the image layer determined experimentally in various panoramic x-ray machines. Oral Surg Oral Med Oral Pathol 1985;60:104-112. [CrossRef]

26. Ledgerton $D$, Horner $K$, Devlin $H$, Worthington $\mathrm{H}$. Radiomorphometric indices of the mandible in a British female population. Dentomaxillofac Radiol 1999;28(3):173-181. [CrossRef]

27. Benson BW, Prihoda TJ, Glass BJ. Variations in adult cortical bone mass as measured by a panoramic mandibular index. Oral Surg Oral Med Oral Pathol 1991;71(3):349-356. [CrossRef]

28. Mckee IW, Williamson PC, Lam EW, Heo G, Glover KE, Major PW. The accuracy of 4 panoramic units in the projection of mesiodistal tooth angulations. Am J Orthod Dentofacial Orthop 2002;121(2):166-175. [CrossRef]

29. Sanderink GC, Visser VN, Kramers EW. The origin of a case severe image distortion in rotational panoramic radiography. Dentomaxillofac Radiol 1991;20:169-171.

30. Laster WS, Ludlow JB, Bailey LJ, Hershey HG. Accuracy of measurements of mandibular anatomy and prediction of asymmetry in panoramic radiographic images. Dentomaxillofac Radiol 2005;34(6):343-349. 
31. Schulze R, Schalldach F, d'Hoedt B. Effect of positioning errors on magnification factors in the mandible in digital panorama imaging. Mund Kiefer Gesichtschir 2000;4(3):164170.

32. Mattila K, Altonen $\mathrm{M}$, Haavikko $\mathrm{K}$. Determination of the gonial angle from the orthopantomogram. Angle Orthod 1977;47(2):107-110.

33. Mckee IW, Glover KE, Williamson PC, Lam EW, Heo G, Major PW. The effect of vertical and horizontal head positioning in panoramic radiography on mesiodistal tooth angulations. Angle Orthod 2001;71(6):442-451. 